\title{
Quality Evaluation of Carburized Surfaces of Steels Used in Military Technology
}

David Dobrocky, Zdenek Joska, Zbynek Studeny, Zdenek Pokorny, Emil Svoboda

Faculty of Military Technology, University of Defence in Brno. Kounicova 65, 60200 Brno. Czech Republic. Email: david.dobrocky@unob.cz

Carburizing is used in applications where there is a high demand for surface hardness and abrasion resistance along with core toughness requirements. Carburizing is mainly used for parts which are subjected to abrasion, such as shafts, pins, gears, cams, etc. At the same time as the hardness of the surface layer increases, the fatigue limit of the steel increases after carburizing. The article deals with the evaluation of surface quality of carburized steels $16 \mathrm{MnCr} 5$ and $14 \mathrm{NiCr} 14$ in terms of surface texture change and dimension change after application of carburizing. The analysed steels are used mainly in the production of gear wheels for gearboxes of wheeled, tracked and artillery. Furthermore, the coefficients of friction and wear were evaluated on these steels. The functional surfaces of heat-treated steels were analysed after grinding and after gas carburizing. The evaluation of the surface quality results in a deterioration of the surface roughness and an increase in dimensions after carburizing. The coefficient of friction after carburizing reaches a higher value compared to ground surfaces, while the coefficient of wear decreases.

Keywords: Surface, Hardness, COF, Texture, Roughness.

\section{Introduction}

The chemical-heat treatment of steels differs from other heat treatment methods in that, besides structural changes, the chemical composition of the surface layer also changes due to the diffusion of certain suitable elements into the steel [1]. Chemical-thermal treatment is most often carried out with the aim of increasing the surface hardness, wear resistance, resistance to cyclic loading (fatigue), or increase the corrosion resistance, eventually increase the surface heat resistance $[2,3]$.

Between chemical-heat treatment technologies that meet the above criteria for increasing the utility properties of functional surfaces of stressed components belongs carburizing. Carburizing is carbonation of the steel surface in a liquid, gaseous or powdery (solid) environment at temperatures above $A_{3}$. The purpose of carburizing is to enrich the surface layer of low-carbon steel (max. up to $0.3 \% \mathrm{C}$ ) with carbon to the under eutectoid, eutectoid or over eutectoid concentration [4]. The resulting surface layer after hardening is characterized by high hardness and abrasion resistance. Carburizing also increases the fatigue resistance $[5,6]$.

The suitability of this chemical-heat treatment process is that a hard martensitic layer is formed on the surface of the carburized part. Nevertheless, the core of the component remains relatively tough, depending on the $\mathrm{C}$ content of the steel, its hardenability and its cross-section [7]. For this reason, carburizing is mainly used for parts which are strain by abrasion (shafts, pins, gears, cams, etc.) [8]. In military technology carburized components are used especially in dynamically highly stressed parts such as gear and disk wheels of gearboxes, auxiliary transmissions, gearboxes, reductions in wheels, differentials and belt gear, as well as engine crankshafts, piston pins, valve lifters, pinions, grooved shafts, pulleys, gear couplings, etc.

At present, modification of carburizing in a gaseous environment, such as vacuum carburizing (LPC low pressure carburizing), is often used. Vacuum carburizing takes place at pressures of $1.3-26.7 \mathrm{kPa}(1-$ 20 Torres) and temperatures of $830^{\circ} \mathrm{C}-980^{\circ} \mathrm{C}$ [8]. It is a non-equilibrium process of carburizing the surface of a component at very low pressure under the action of a partial pressure of gaseous hydrocarbons, in which the carbonation and diffusion regions alternate. Compared to standard carburizing in gas, vacuum carburizing has the advantage of more precise control of the carburizing process and an exactly controllable layer thickness. Another advantage of vacuum carburizing is that essentially no intercrystalline oxidation occurs in vacuum furnaces. Also, the times required to achieve an equally thick carburized layer are shorter [10]. Vacuum carburizing is mainly used in the automotive industry, thanks to the cleanliness of the working environment and the cleanliness of the components after carburizing. Thanks to gas quenching, the components do not need to be scrubbed after carburizing to remove dirt that adheres to the surface after quenching in oil. Gas-quenched components in vacuum furnaces suffer less deformation than after quenching in oil [11]. 
This paper deals with the evaluation of surface quality of carburizing steels $16 \mathrm{MnCr} 5$ and $14 \mathrm{NiCr} 14$, which are used in a wide range of applications in military technology. Carburizing applied to ground surfaces usually causes a change in the texture of the surface, which affects the functional properties of the surface (friction and wear, noise, lubricating properties). In addition, the dimensions of the components are increased, leading to changes in the tolerance classes (e.g. gear wheels) and the need for additional grinding operations. Vacuum carburizing largely eliminates these negatives, compared to conventional carburizing in gas, but fails to eliminate them completely.

\section{Results and discussion}

Experimental samples of $90 \mathrm{~mm}$ x $30 \mathrm{~mm}$ x $20 \mathrm{~mm}$ were made from selected steels (see Fig. 1). Ten samples were made from each steel, five pieces for analysis of ground surfaces and five pieces for analysis of carburized surfaces.

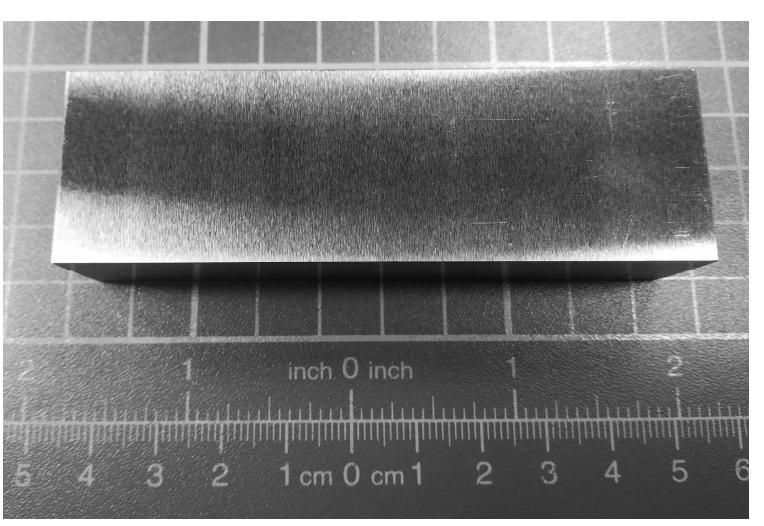

Fig. 1 Experimental sample

\subsection{Chemical composition analysis}

In the evaluated steels, the chemical composition was first analyzed. Chemical composition analysis was performed on a Bruker-Quatron optical emission spectrometer labeled Tasman Q4. The results of the chemical composition and its comparison with the standards are documented in Table 1.

Tab. 1 Chemical composition of evaluated steels $16 \mathrm{MnCr} 5$ and $14 \mathrm{NiCr14}$ [wt.\%]

\begin{tabular}{|c|c|c|c|c|c|c|c|}
\hline 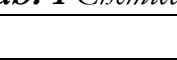 & & & & Elements & & & \\
\hline Steel & C & Mn & Si & $\mathrm{Cr}$ & $\mathbf{N i}$ & $\mathbf{P}$ & $\mathbf{S}$ \\
\hline \multirow{4}{*}{$16 \mathrm{MnCr} 5$} & \multicolumn{7}{|c|}{ DIN Standard } \\
\hline & $0.14-0.19$ & $1.10-1.40$ & $0.17-0.37$ & $0.80-1.10$ & - & $\max .0 .035$ & $\max .0 .035$ \\
\hline & \multicolumn{7}{|c|}{ Tasman Q4 } \\
\hline & 0.15 & 1.19 & 0.26 & 1.05 & 0.39 & 0.009 & 0.005 \\
\hline \multirow{4}{*}{ 14NiCr14 } & \multicolumn{7}{|c|}{ DIN Standard } \\
\hline & $0.10-0.17$ & $0.30-0.60$ & $0.17-0.37$ & $0.60-0.90$ & $3.20-3.70$ & $\max .0 .035$ & $\max .0 .035$ \\
\hline & \multicolumn{7}{|c|}{ Tasman Q4 } \\
\hline & 0.07 & 0.60 & 0.27 & 0.80 & 3.35 & 0.009 & 0.006 \\
\hline
\end{tabular}

\subsection{Heat treatment and chemical-heat treatment}

Heat treatment of steels consisted of normalization annealing, quenching and tempering. Normalization annealing is a necessary heat treatment of steels before quenching and tempering. The aim of the heat treatment was to obtain a sorbitic structure with a favorable combination of mechanical properties. The sorbitic structure can only be created by tempering martensite. This structure was required for the reference

(ground) samples, but the same process of heat treatment was applied in case of samples before carburizing (all samples were placed in one batch.). In order to prevent anisothermal embrittlement of the evaluated steels, the samples were rapidly cooled into water after tempering. During rapid cooling, the precipitation of fine particles of complex carbides along the boundaries of the martensitic needles, which lie along the original boundaries of the austenitic grains, is limited [12]. The heat treatment parameters are given in Table 2.

Tab. 2 Parameters of heat treatment of steels $16 \mathrm{MnCr} 5$ and $14 \mathrm{NiCr} 14$

\begin{tabular}{|c|c|c|c|}
\hline & \multicolumn{3}{|c|}{ Parameters of heat-treatment } \\
\hline Steel & Normalization annealing & Quenching & Tempering \\
\hline 16MnCr5 & $910^{\circ} \mathrm{C} / 45 \mathrm{~min} /$ air & $870^{\circ} \mathrm{C} / 45 \mathrm{~min} /$ water & $600{ }^{\circ} \mathrm{C} / 100 \mathrm{~min} / \mathrm{water}$ \\
\hline $\mathbf{1 4 N i C r 1 4}$ & $850^{\circ} \mathrm{C} / 45 \mathrm{~min} /$ air & $840^{\circ} \mathrm{C} / 45 \mathrm{~min} / \mathrm{water}$ & $600^{\circ} \mathrm{C} / 100 \mathrm{~min} / \mathrm{water}$ \\
\hline
\end{tabular}

Evaluated surfaces of experimental samples after heat treatment were ground on a surface grinder $\mathrm{BPH}$ 300 with the aim to achieve surface roughness $\mathrm{Ra}=$ $0.4 \mu \mathrm{m}$. The speed of the grinding wheel was set to $2400 \mathrm{rpm}$, the table shift was $10 \mathrm{~m} / \mathrm{min}$, the grinding wheel type 98A46J9V40 (J hardness). During grinding, the ground surfaces were cooled with Idazox HB 20 coolant. The concentration of coolant was 5\% (1:20).

Vacuum carburizing was carried out in the BMI furnace. The parameters of carburizing are shown in Table 3. 
Tab. 3 Parameters of carburizing of steels $16 \mathrm{MnCr} 5$ and $14 \mathrm{NiCr} 14$

\begin{tabular}{|c|c|c|c|}
\hline Temperature $\left[{ }^{\circ} \mathbf{C}\right]$ & Pressure $[\mathbf{P a}]$ & Time $[\mathbf{h}]$ & Atmosphere \\
\hline 1000 & $102-104$ & 1 & Methan \\
\hline
\end{tabular}

\subsection{Metallographic analysis}

Metallographic evaluation of experimental samples was performed after chemical-heat treatment. The analysis included an assessment of the resulting structure after heat and chemical-heat treatment, which is illustrated in Fig. 2 and Fig. 3. Metallographic analysis was performed using an Olympus Lext OLS 3000 laser confocal microscope. In the case of $16 \mathrm{MnCr} 5$

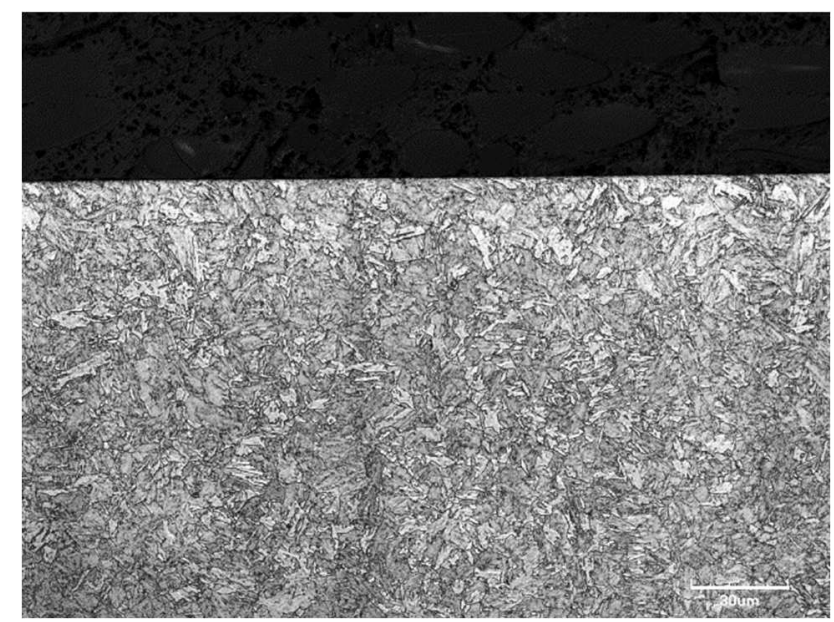

$$
\text { Tempered }
$$

Nital 5\% steel, the structure consists of tempered martensite and sorbite after tempering. The same structure was achieved also with $14 \mathrm{NiCr} 14$ steel. A lower magnification for carburized steels was chosen to document the entire carburized layer. The $16 \mathrm{MnCr} 5$ steel shows the eutectoid composition of the carburized layer which passes into the core of the part without a distinct under eutectoid layer. The eutectoid and under eutectoid composition of the carburized layer is apparent in $14 \mathrm{NiCr} 14$ steel.

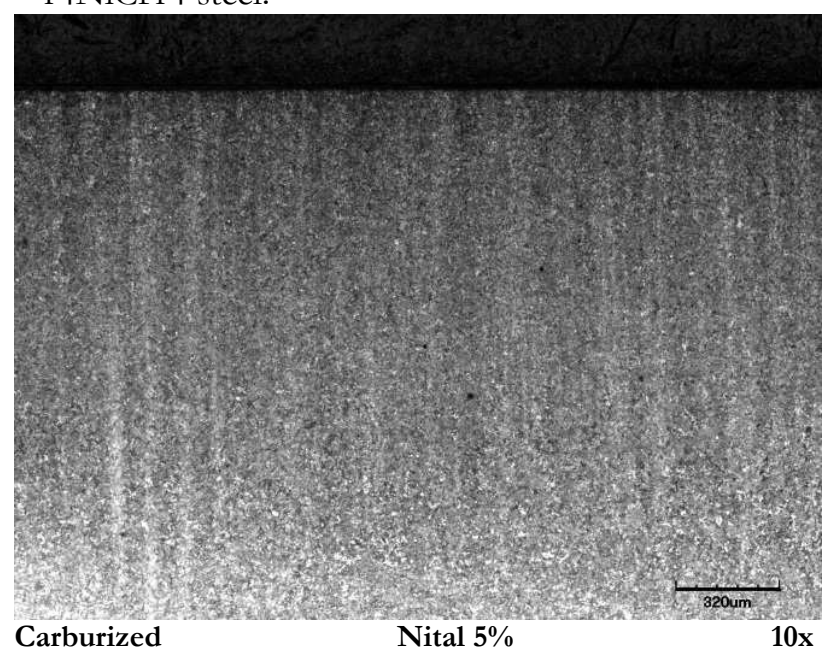

Fig. 2 Microstructure of $16 \mathrm{MnCr} 5$ steel

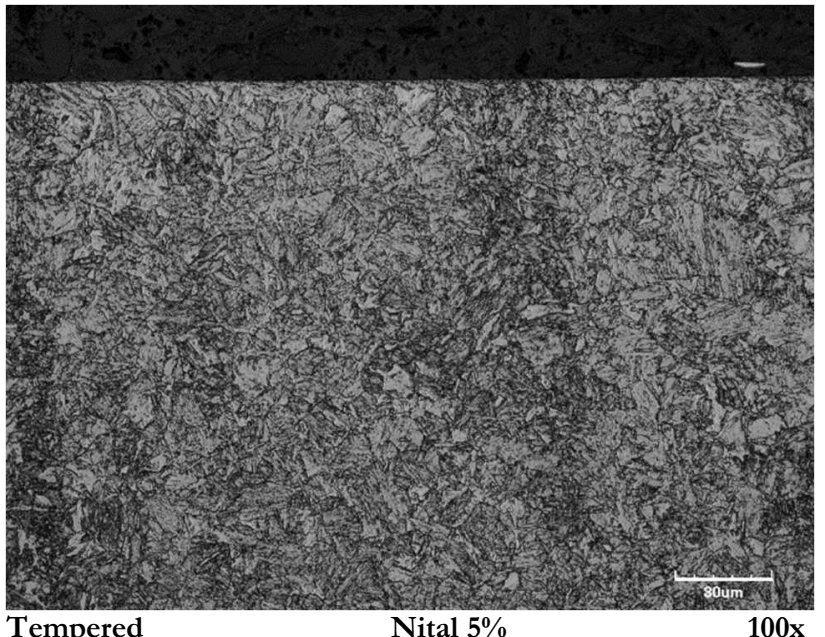

Tempered
Nital 5\%

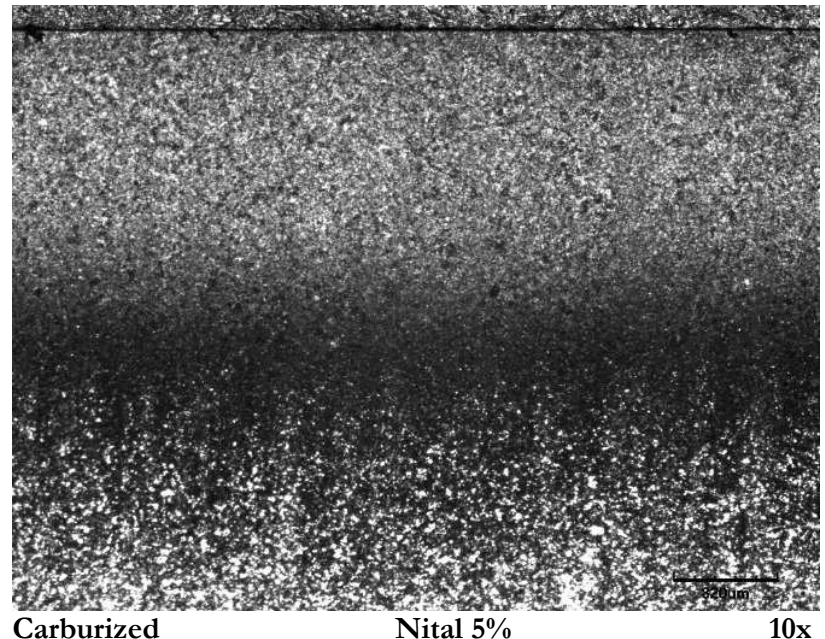

Nital $5 \%$
$10 \mathrm{x}$

Fig. 3 Microstructure of $14 \mathrm{NiCr14}$ steel

\subsection{Measurement of carburized layer depth}

The depth of the carburized layer was documented by an indirect microhardness measurement method on an LM 247AT Leco automated microhardness tester using a load of $1000 \mathrm{~g}$ (HV 1) for $10 \mathrm{~s}$. The layer depth reference value was selected in accordance with
ISO 18203 at $550 \mathrm{HV}$ [13]. Five measurements were made on each steel. In the case of $16 \mathrm{MnCr} 5$ steel the depth of the carburized layer was measured on value $1.19 \mathrm{~mm} \pm 0.013 \mathrm{~mm}$, in the case of $14 \mathrm{NiCr} 14$ the depth of the carburized layer was $1.11 \mathrm{~mm} \pm 0.014$ mm. Figures 4 and 5 show the microhardness curves of selected measurements of evaluated steels. 


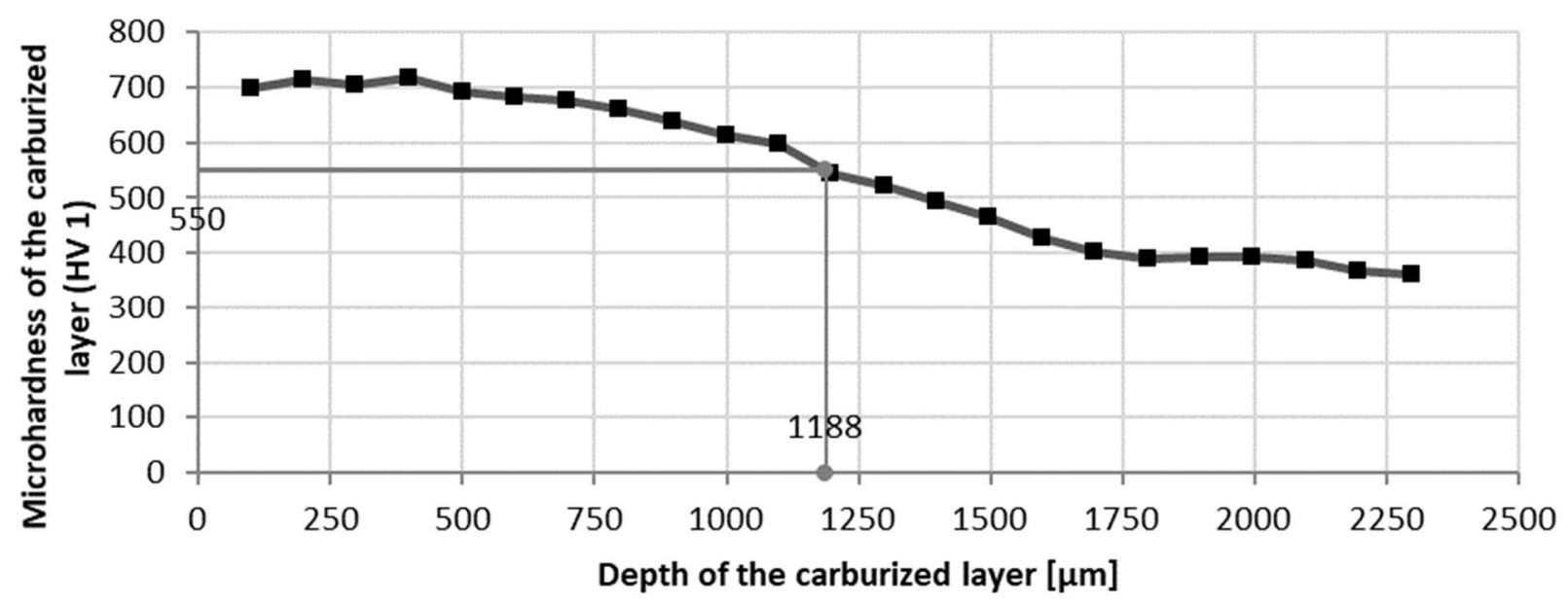

Fig. 4 The course of microhardness of carburized layer- steel $16 \mathrm{MnCr} 5$

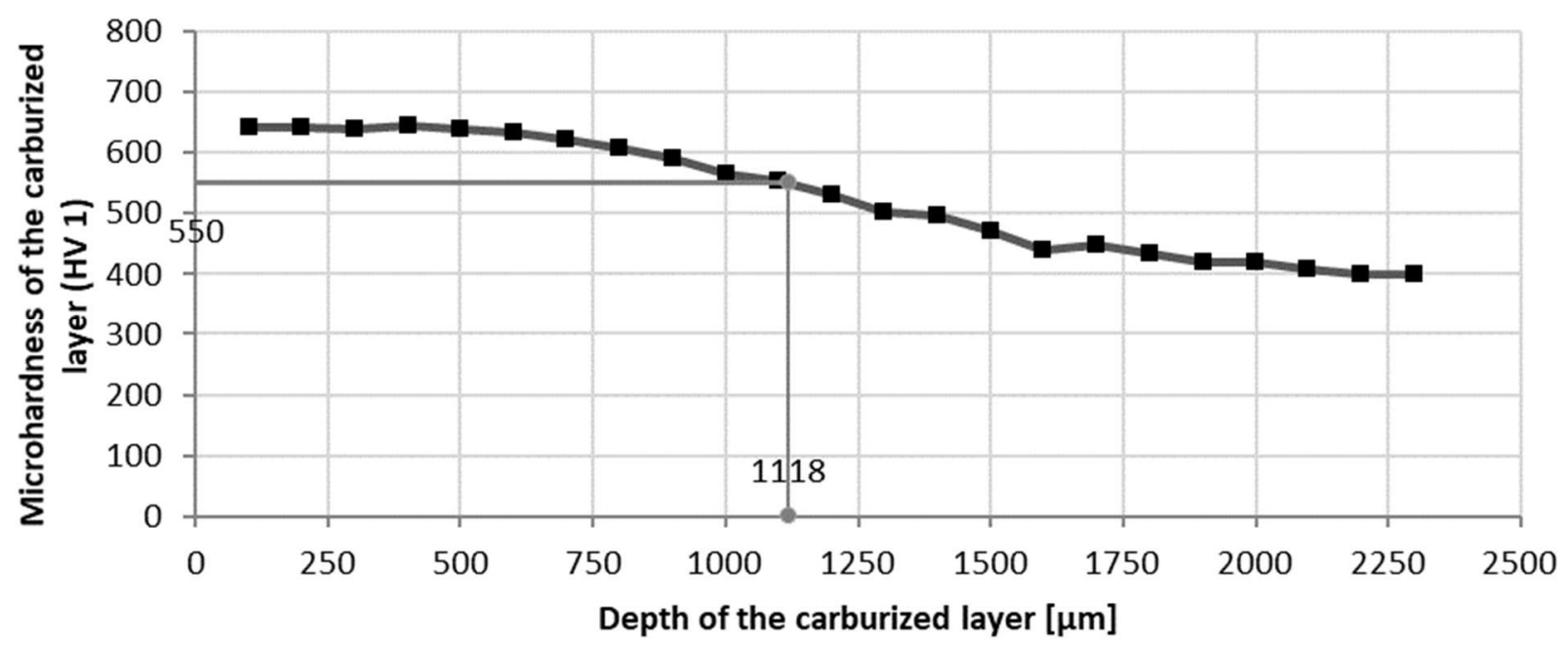

Fig. 5 The course of microhardness of carburized layer - steel 14NiCr14

\subsection{Measurement of surface hardness}

One of the important parameters of the surface layer is its hardness. Surface hardness was measured by the Vickers method. The load value was selected 10 $\mathrm{kg}$ (HV 10), load time $10 \mathrm{~s}$. The measurement was per- formed on a LECO LV800AT hardness tester. Surface hardness measurements were performed on three samples, always at three locations on each sample. The graph of Fig. 6 shows the results of the surface hardness measurement. It is clear from the results of the surface hardness measurement that both steels reached to a three-fold increase in surface hardness.

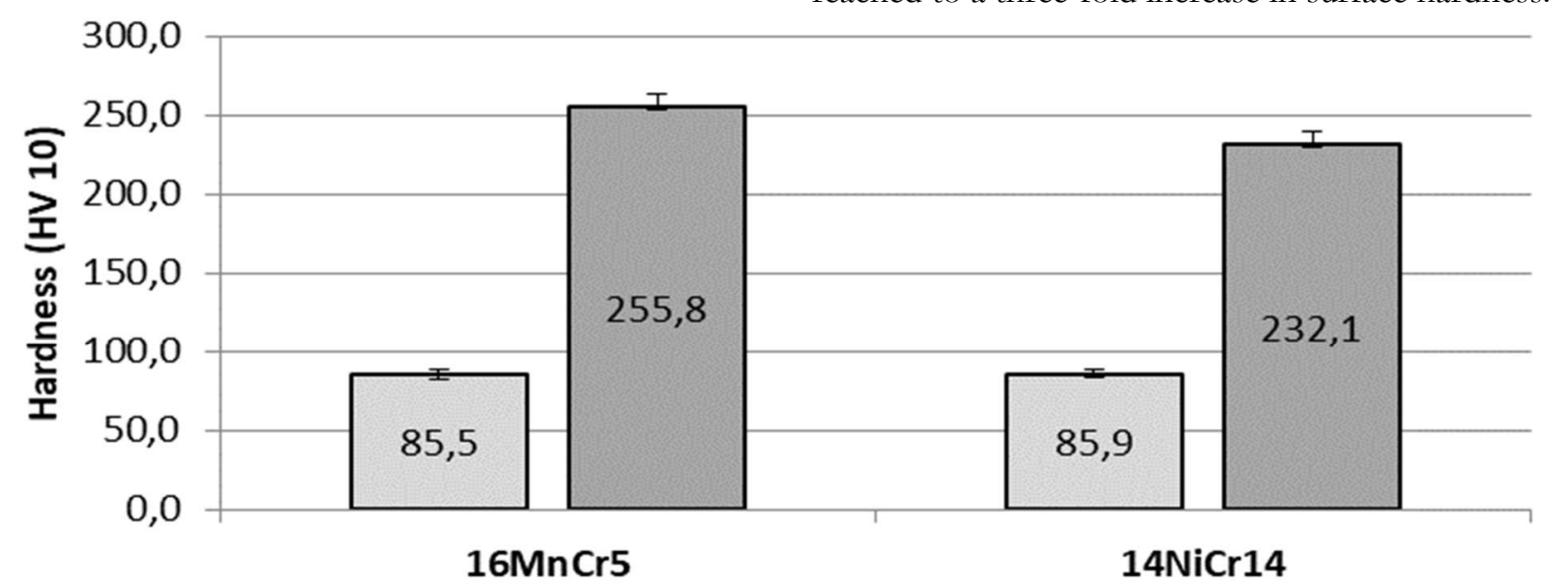

$\square$ Ground $\square$ Carburized

Fig. 6 Results of surface hardness measurement 
2.6 Measurement of friction coefficient and scratch resistence

Furthermore, the coefficient of friction $(\mathrm{COF})$ and scratch resistance were evaluated in experimental samples. The friction coefficient was measured by a scratch test on a Bruker UMT-3 tribometer. The scratch test was performed on three tempered samples with ground surfaces and on three carburized samples from each steel. Three measurements were performed on each sample. Table 4 shows the scratch test parameters. The results of the friction coefficient measurements are shown graphically in Fig. 7.

Tab. 4 Scratch test parameters

\begin{tabular}{|c|c|c|c|c|c|}
\hline Indenter & Tip radius & Cone angle & Load & Speed & Track length \\
\hline Rockwell & $200 \mu \mathrm{m}$ & $120^{\circ}$ & $100 \mathrm{~N}$ & $0.20 \mathrm{~mm} / \mathrm{s}$ & $10 \mathrm{~mm}$ \\
\hline
\end{tabular}

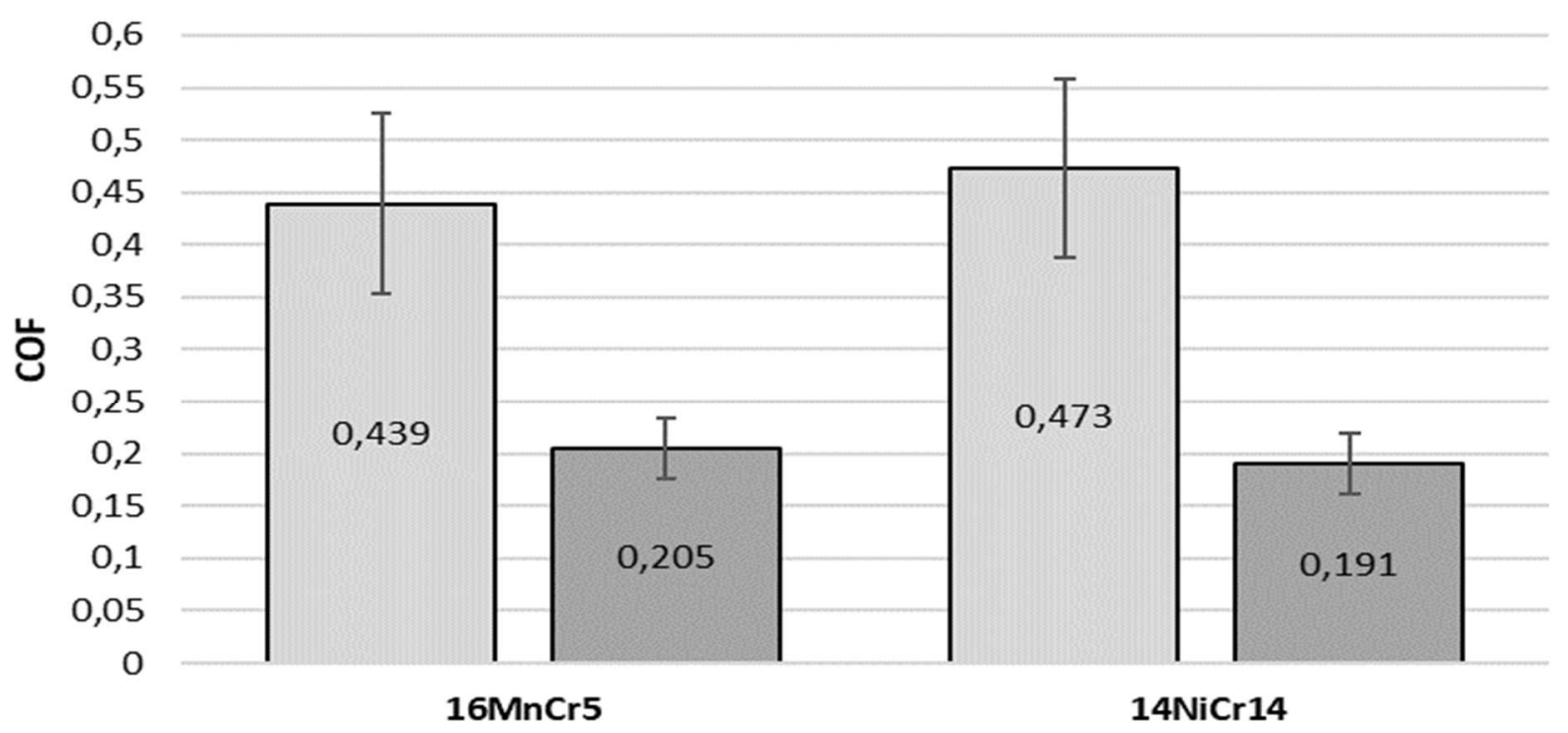

$\square$ Ground $\square$ Carburized

Fig. 7 Results of coefficient of friction (COF)

The results of Fig. 7 show a decrease in the coefficient of friction of the carburized surfaces of both steels, which is more than $100 \%$.

The scratch resistance of ground and carburized surfaces was calculated according to the formula [14]:

$$
H S_{P}=\frac{8 P}{\pi w^{2}}
$$

Where: $H S_{P}$ - scratch hardness number (GPa), $P$ normal force $(\mathrm{N})$ and $w$ - scratch width (m).

The scratch resistance involves applying the scratch to the surface of the experimental sample by moving the indenter along a specific path at constant normal force and constant speed. The value of the average scratch width is used to calculate the degree of surface hardness in units of pressure. The higher the pressure value of the indenter penetration into the material being evaluated, the higher the scratch resistance.

The width of the wear trace w, necessary for the calculation of the scratch resistance, was obtained by measuring scratches generated by the scratch test (Fig. 8), using an inductive touch sensor on the universal measuring machine TalySurf CLI 1000. Three measurements were taken at each scratch at $2 \mathrm{~mm}, 5 \mathrm{~mm}$ and $8 \mathrm{~mm}$ distances from the start of the scratch. The wear trace widths were evaluated using the TalyMap software (Fig. 9).

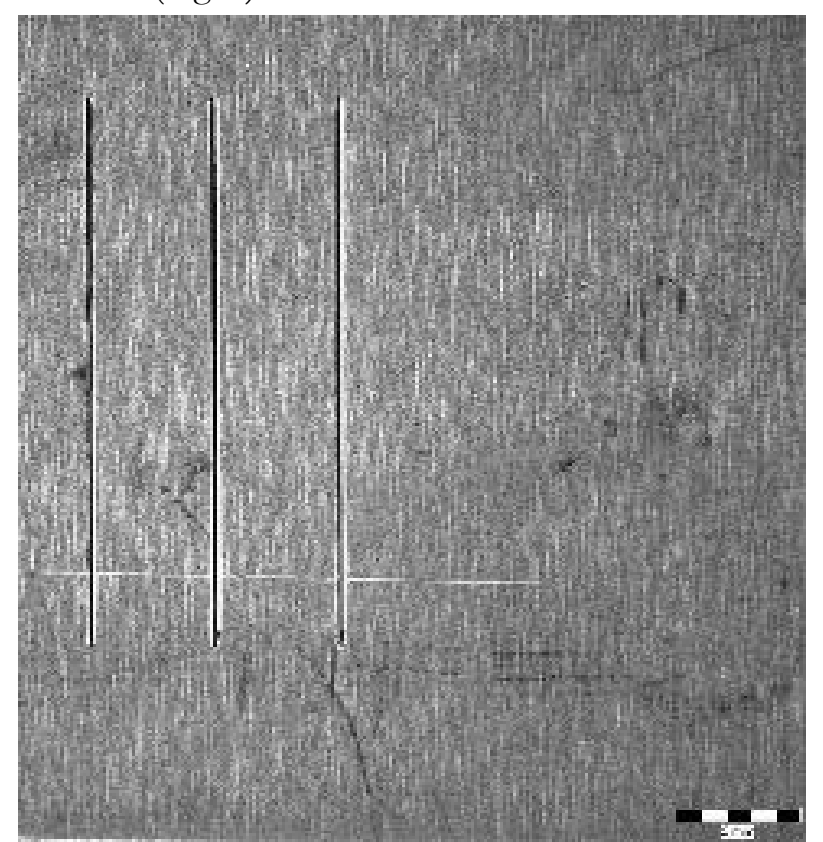

Fig. $\boldsymbol{8}$ Traces of wear on the ground surface of the experimental sample, magnified $6.3 x$ 


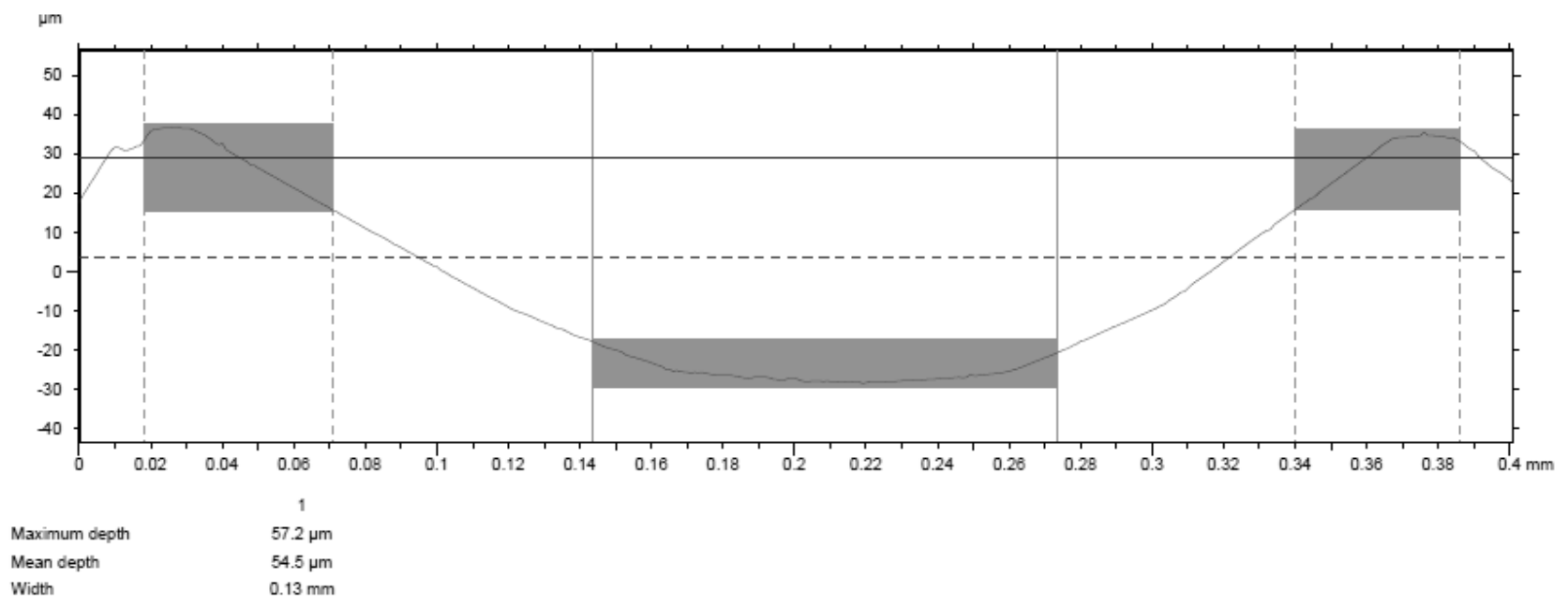

Fig. 9 Display of wear trace width measurement with TalyMap software

The results of scratch resistance of evaluated steels are summarized in the graph in Fig. 10. It is apparent from the graph that the scratch resistance of carburized samples increased almost three times compared to ground surfaces of tempered steels. The achieved values of scratch resistance of the surface reached almost the same values for both types of surfaces in both analyzed steels. The scratch resistance results correlate with the surface hardness measurement results (see Fig. 6).

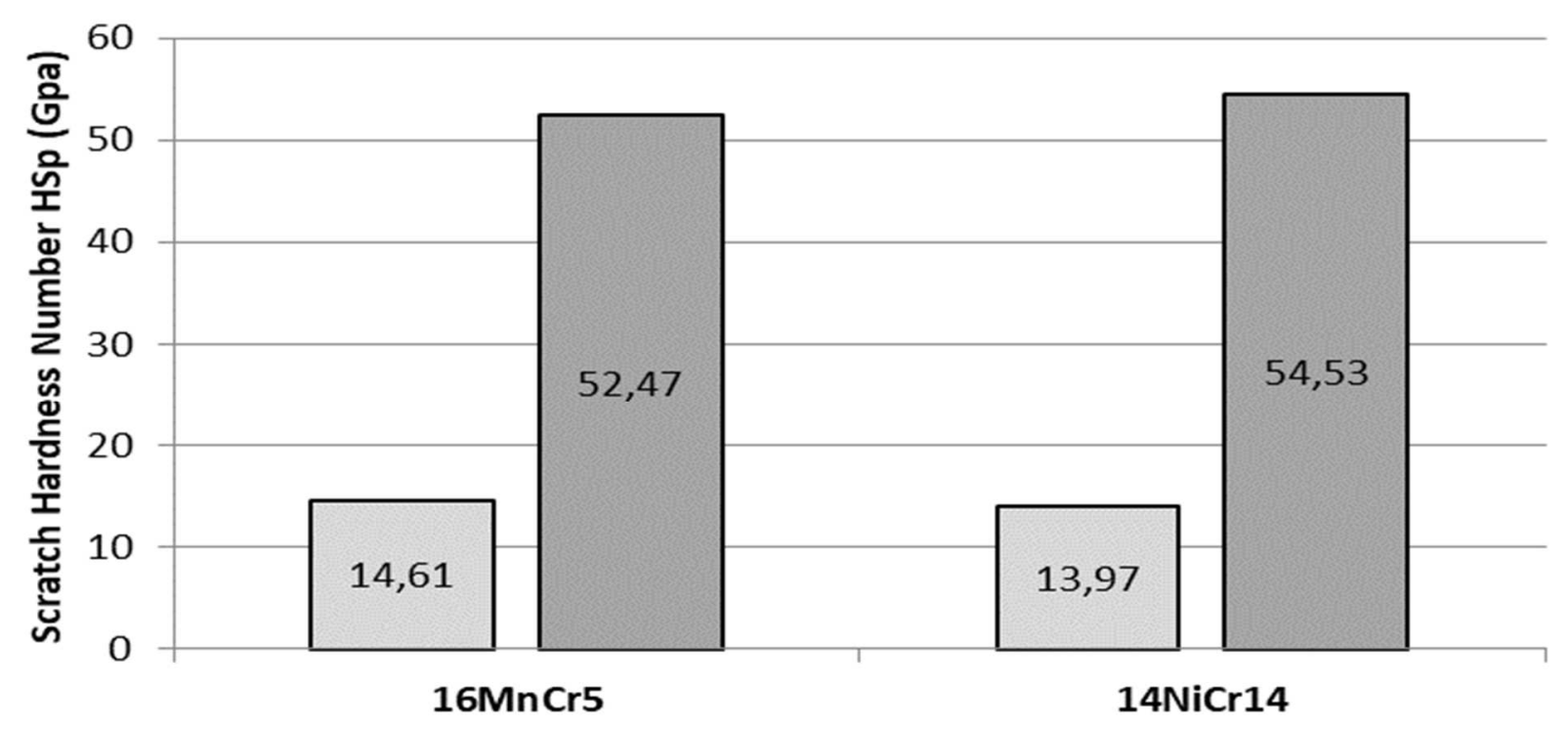

$\square$ Ground $\square$ Carburized

Fig. 10 - Scratch resistance of evaluated steels

\subsection{Measurement of dimensions}

All experimental samples of both steels were dimensionally measured after heat treatment. The foreheads of the samples, as well as the remaining surfaces, were ground. The aim of the measurement was to determine the increase in the size of experimental samples after cementation between the foreheads of samples. The measurement was carried out using a touch sensor and a Werth ScopeCheck 3D coordinate measuring machine (see Fig. 11). The measurement consisted of placing the sample on the measuring table, levelling it in the coordinate system, and creating the measurement strategy. The distance of both sample foreheads was measured, and 25 points were measured at each sample forehead, which was used to create a plane in the WinWerth software. The same procedure was repeated on the other side of the sample. The center distance of both planes was evaluated as the reference distance of the forehands of samples.

The results of the measurement of the dimensions increase after carburizing are documented by the graph in Fig. 12. The graph shows that the experimental samples of $16 \mathrm{MnCr} 5$ steel achieved a length increase of $0.015 \mathrm{~mm}$ after carburizing. In case 
of14NiCr14 steel, the dimensional increase was 0.047 $\mathrm{mm}$ after carburizing.

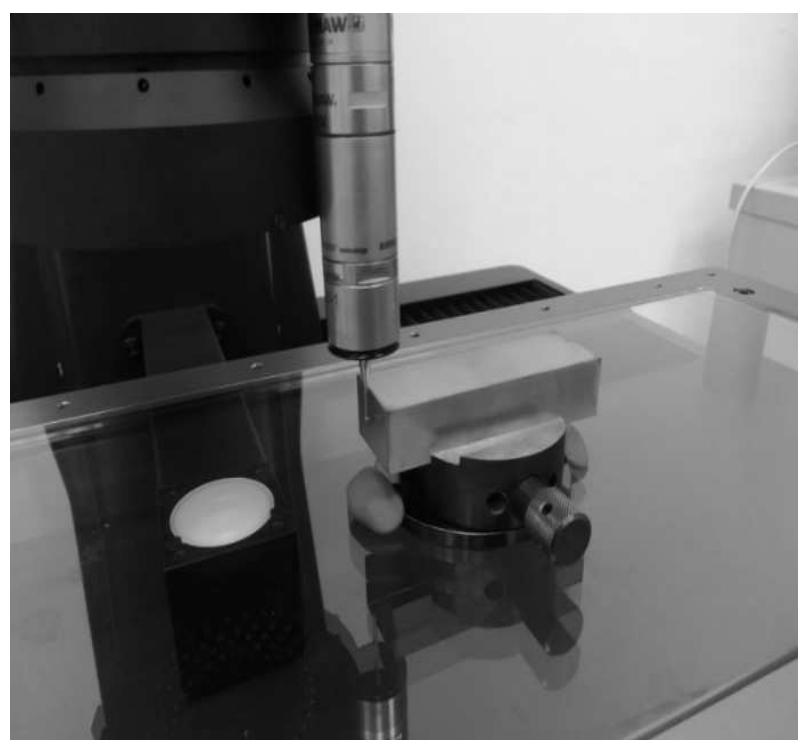

Fig. 11 Measurement of dimensions of experimental samples

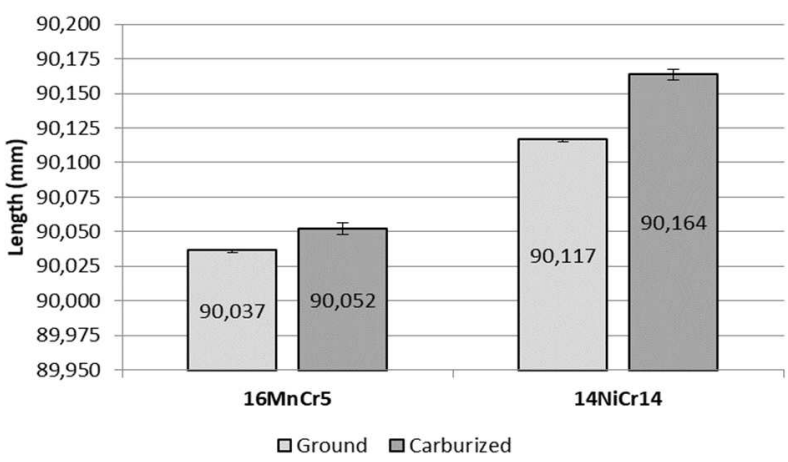

Fig. 12 Results of measurement of changes of the dimensions of experimental samples

\subsection{Measurement of surface texture}

Together with increasing of the dimensions of carburized samples, the texture of the surface was changed. Texture analysis was performed using a coherent correlation interferometer TalySurf CCI Lite and evaluated using the TalyMap Platinum software. Table 5 shows the basic measurement parameters.

Tab. 5 Surface texture measurement parameters

\begin{tabular}{|c|c|c|c|}
\hline Measured area & $\begin{array}{c}\text { Number of roughness } \\
\text { profiles }\end{array}$ & Resolution & Filtration \\
\hline $0.8 \mathrm{~mm} \times 0.8 \mathrm{~mm}$ & 1024 & $0.1 \mathrm{~nm}$ & Gauss $-0.8 \mathrm{~mm}$ \\
\hline
\end{tabular}

The change in surface roughness was analysed by the amplitude parameters Ra, Rq, Rz and Rt, the surface waviness was analysed by the amplitude parameters $\mathrm{Wa}, \mathrm{Wq}, \mathrm{Wz}$ and $\mathrm{Wt}$. The roughness profiles of the ground surfaces and surfaces after carburizing of the experimental samples are for both steels illustrated in Figures 13 and 14. This is the mean roughness profile from a total of 1024 profiles.
The carburized surface of the $16 \mathrm{MnCr} 5$ steel sample shows more dominant peaks and valleys than the ground surface.

The ground and carburized surface of $14 \mathrm{NiCr} 14$ steel shows similar microgeometry. However, sharper peaks are visible on the carburized surface.

The results of surface roughness and waviness measurements are shown in Table 6 for $16 \mathrm{MnCr} 5$ steel and Table 7 for $14 \mathrm{NiCr} 14$ steel.

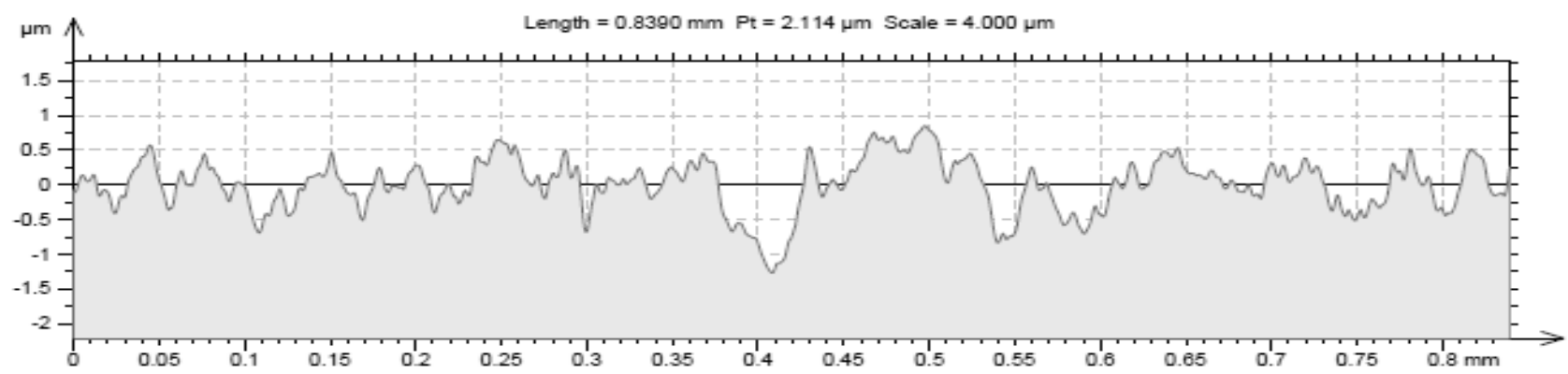

a)

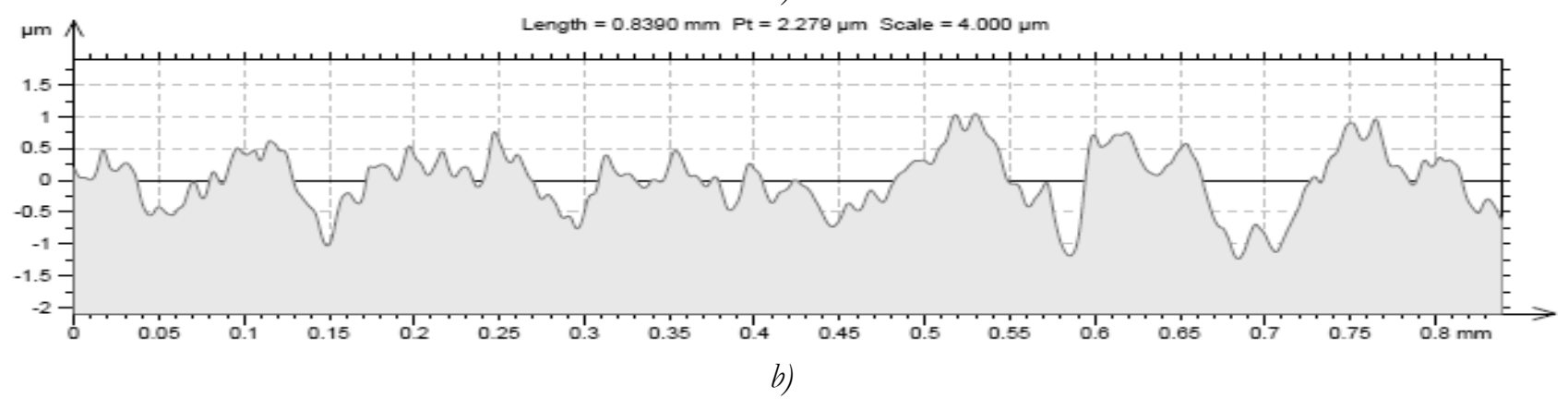

Fig. 13 Surface roughness profiles of steel 16MnCr5; a) ground surface, b) carburized surface 

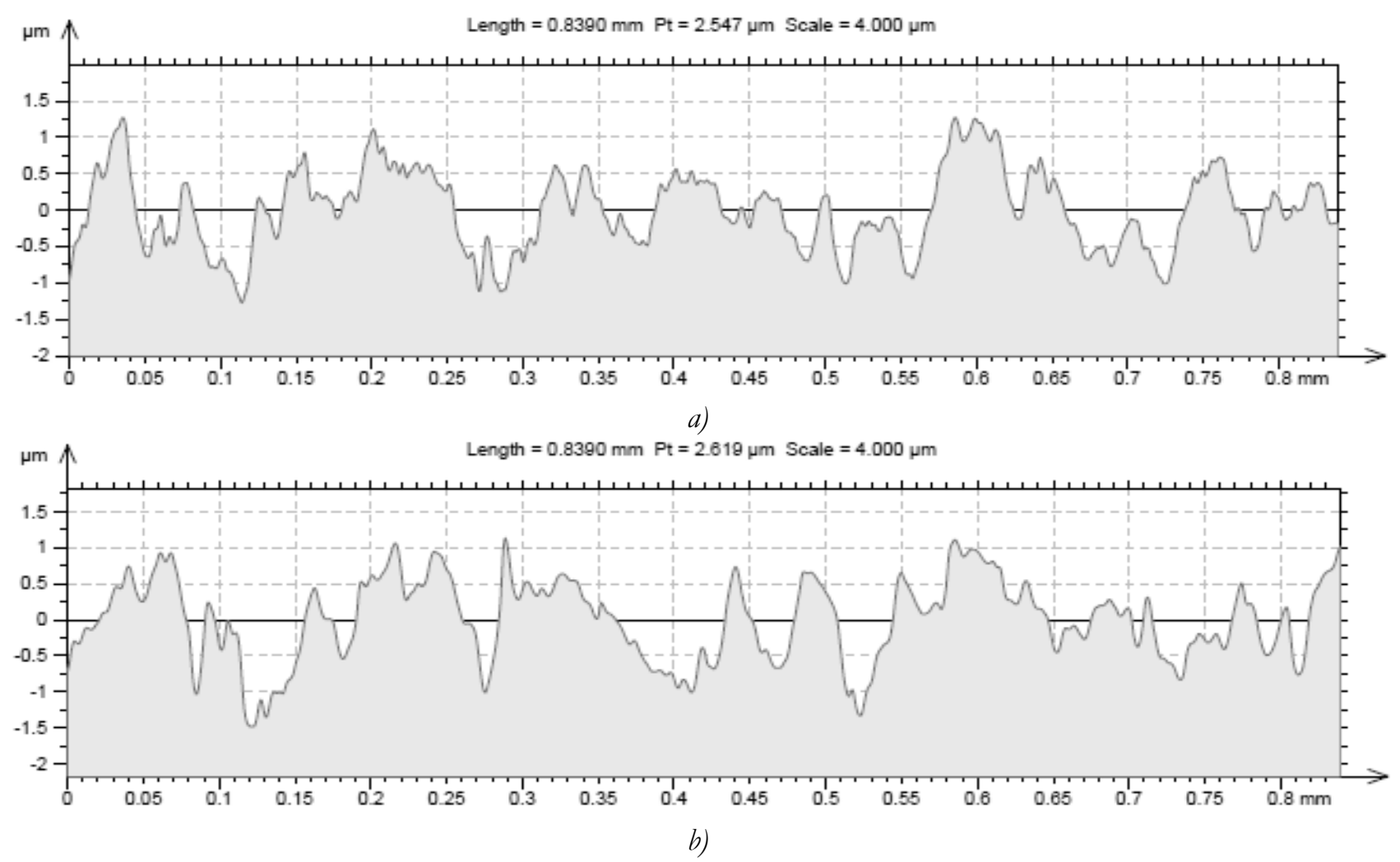

Fig. 14 Surface roughness profiles of steel 14NiCr14; a) ground surface, b) carburized surface

The difference in surface roughness of $16 \mathrm{MnCr} 5$ steel is not significant for the ground and carburized surface. Greater difference was measured for peak parameters $\mathrm{Rz}$ and $\mathrm{Rt}$, which indicates higher peaks and deeper valleys for the carburized surface. This can cause the formation of more frictional particles in the running-in of the carburized parts (the tip of the peaks breaks under load), eventually greater deformation of the loaded surface. The waviness parameters did not change after carburizing and correspond to the ground surfaces.

Tab. 6 Results of surface roughness and waviness parameters of steel $16 \mathrm{MnCr} 5$

\begin{tabular}{|c|c|c|c|}
\hline \multirow{2}{*}{ Parameter } & \multicolumn{2}{|c|}{ 16MnCr5 } & \multirow{2}{*}{ Difference $(\boldsymbol{\mu m})$} \\
\cline { 2 - 3 } & Ground $(\boldsymbol{\mu m})$ & Carburized $(\boldsymbol{\mu m})$ & 0.09 \\
\hline $\mathrm{Ra}$ & $0.37 \pm 0.03$ & $0.46 \pm 0.04$ & 0.11 \\
\hline $\mathrm{Rq}$ & $0.46 \pm 0.04$ & $0.57 \pm 0.04$ & 0.43 \\
\hline $\mathrm{Rz}$ & $2.19 \pm 0.15$ & $2.62 \pm 0.17$ & 0.46 \\
\hline $\mathrm{Rt}$ & $2.64 \pm 0.19$ & $3.10 \pm 0.20$ & 0.00 \\
\hline $\mathrm{Wa}$ & $0.11 \pm 0.03$ & $0.11 \pm 0.03$ & 0.01 \\
\hline $\mathrm{Wq}$ & $0.12 \pm 0.03$ & $0.13 \pm 0.03$ & 0.00 \\
\hline $\mathrm{Wz}$ & $0.37 \pm 0.10$ & $0.37 \pm 0.09$ & 0.01 \\
\hline $\mathrm{Wt}$ & $0.51 \pm 0.14$ & $0.52 \pm 0.10$ & \\
\hline
\end{tabular}

Tab. 7 Results of surface roughness and waviness parameters of steel 14NiCr14

\begin{tabular}{|c|c|c|c|}
\hline \multirow{2}{*}{ Parameter } & \multicolumn{2}{|c|}{ 14NiCr14 } & \multirow{2}{*}{ Difference $(\boldsymbol{\mu m})$} \\
\cline { 2 - 3 } & Ground $(\boldsymbol{\mu m})$ & Carburized $(\boldsymbol{\mu m})$ & 0.02 \\
\hline $\mathrm{Ra}$ & $0.51 \pm 0.04$ & $0.53 \pm 0.06$ & 0.00 \\
\hline $\mathrm{Rq}$ & $0.66 \pm 0.05$ & $0.66 \pm 0.07$ & 0.03 \\
\hline $\mathrm{Rz}$ & $3.00 \pm 0.21$ & $3.03 \pm 0.29$ & 0.13 \\
\hline $\mathrm{Rt}$ & $3.35 \pm 0.17$ & $3.48 \pm 0.27$ & 0.06 \\
\hline $\mathrm{Wa}$ & $0.14 \pm 0.03$ & $0.20 \pm 0.02$ & 0.07 \\
\hline $\mathrm{Wq}$ & $0.16 \pm 0.04$ & $0.23 \pm 0.02$ & 0.18 \\
\hline $\mathrm{Wz}$ & $0.47 \pm 0.09$ & $0.65 \pm 0.06$ & 0.16 \\
\hline $\mathrm{Wt}$ & $0.66 \pm 0.17$ & $0.82 \pm 0.09$ & \\
\hline
\end{tabular}


In the case of $14 \mathrm{NiCr} 14$ steel, the same surface roughness values as for ground surfaces were achieved after carburizing. A slight increase in values was observed only for the parameter Rt, which may be caused by a unique random peak. Significant differences were achieved in the case of surface waviness, which increased in the monitored parameters after carburizing.
In addition to 2D parameters, 3D surface parameters were analysed for a more comprehensive description of surface microgeometry. From 3D parameters were selected $\mathrm{Sa}, \mathrm{Sq}, \mathrm{Sz}$ and $\mathrm{St}$, which are equivalents to $2 \mathrm{D}$ roughness parameters. However, 3D parameters are related to the whole evaluated area. Tables 8 and 9 show the results of measuring 3D surface parameters.

Tab. 8 Results of $3 D$ parameters of surface texture - steel $16 \mathrm{MnCr} 5$

\begin{tabular}{|c|c|c|c|}
\hline \multirow{2}{*}{ Parameter } & \multicolumn{2}{|c|}{ 16MnCr5 } & \multirow{2}{*}{ Difference $(\boldsymbol{\mu m})$} \\
\cline { 2 - 3 } & Ground $(\boldsymbol{\mu m})$ & Carburized $(\boldsymbol{\mu m})$ & 0.10 \\
\hline $\mathrm{Sa}$ & $0.41 \pm 0.03$ & $0.51 \pm 0.05$ & 0.11 \\
\hline $\mathrm{Sq}$ & $0.53 \pm 0.02$ & $0.64 \pm 0.07$ & 0.18 \\
\hline $\mathrm{Sz}$ & $3.04 \pm 0.16$ & $3.22 \pm 0.21$ & 0.17 \\
\hline $\mathrm{St}$ & $3.06 \pm 0.13$ & $3.23 \pm 0.27$ & \\
\hline
\end{tabular}

Tab. 9 Results of $3 \mathrm{D}$ parameters of surface texture - steel $14 \mathrm{NiCr} 14$

\begin{tabular}{|c|c|c|c|}
\hline \multirow{2}{*}{ Parameter } & \multicolumn{2}{|c|}{ 14NiCr14 } & \multirow{2}{*}{ Difference $(\boldsymbol{\mu m})$} \\
\cline { 2 - 3 } & Ground $(\boldsymbol{\mu m})$ & Carburized $(\boldsymbol{\mu m})$ & 0.01 \\
\hline $\mathrm{Sa}$ & $0.61 \pm 0.05$ & $0.62 \pm 0.02$ & 0.02 \\
\hline $\mathrm{Sq}$ & $0.75 \pm 0.06$ & $0.77 \pm 0.05$ & 0.05 \\
\hline $\mathrm{Sz}$ & $3.88 \pm 0.19$ & $3.93 \pm 0.24$ & 0.06 \\
\hline $\mathrm{St}$ & $3.88 \pm 0.11$ & $3.94 \pm 0.18$ & \\
\hline
\end{tabular}

It is clear from the results of 3D surface area measurements that the evaluated parameters slightly increased after carburizing of $16 \mathrm{MnCr} 5$ steel. In case of $14 \mathrm{NiCr} 14$ steel the increase of evaluated parameters is negligible and it can be said that 3D surface parameters did not change after carburizing.

\section{Conclusion}

The article dealt with the evaluation of the quality of carburized surfaces of $16 \mathrm{MnCr} 5$ and $14 \mathrm{NiCr} 14$ steels, which are widely used in applications for military technology. A progressive vacuum carburizing method was chosen for chemical-heat treatment, which, compared to other carburizing methods, causes a minimal increase in the dimensions of the carburized parts. The following conclusions can be drawn from the results achieved:

- a similar depth of the carburized layer was achieved in both steels at use of the same parameters of carburizing process,

- $\quad$ surface hardness increased by $170.3 \mathrm{HV} 10$ for $16 \mathrm{MnCr} 5$ steel and $146.2 \mathrm{HV} 10$ for $14 \mathrm{NiCr} 14$ steel after carburizing,

- for carburized surfaces, the coefficient of friction (COF) decreased by 0.234 for $16 \mathrm{MnCr} 5$ steel and by 0.282 for $14 \mathrm{NiCr} 14$ steel,

- carburizing resulted in an increase in the scratch resistance value of HSp by $37.86 \mathrm{GPa}$ for $16 \mathrm{MnCr} 5$ steel and $40.56 \mathrm{GPa}$ for 14NiCR14 steel,

- carburizing resulted in an increase in the dimensions of the experimental samples by $0.015 \mathrm{~mm}(16 \mathrm{MnCr} 5$ steel) and $0.047 \mathrm{~mm}$ $(14 \mathrm{NiCr} 14$ steel),

- $16 \mathrm{MnCr} 5$ steel occurred to slightly increase roughness after carburizing, the waviness parameters remained the same as for ground surfaces,

- $\quad 14 \mathrm{NiCr} 14$ steel achieved the same roughness parameters after carburizing as for ground surfaces, the waviness parameters slightly increased,

- for steel $16 \mathrm{MnCr} 5$ a slight increase of 3D surface parameters was achieved after carburizing, these parameters remained almost unchanged in case of steel $14 \mathrm{NiCr} 14$.

The results show the suitability of the selected chemical-heat treatment technology for selected steels, which leads to an increase in mechanical parameters affecting the service life of functional surfaces. The selected type of carburizing led only to a slight increase in surface roughness and waviness of selected steels and to a small increase in dimensions. 


\section{Acknowledgement}

The work presented in this paper has been supported by the specific research project 2018 „SV18-216“ at the Department of Mechanical Engineering, University of Defence in Brno and the Project for the Development of the Organization „DZRO K201“.

\section{References}

[1] YOU, Y., YAN, J., YAN. M. (2019). Atomistic diffusion mechanism of rare earth carburizing/nitriding on iron-based alloy. In: Applied Surface Science, Vol. 484, 2019, p. 710-715. ISSN: 0169-4332.

[2] FALTEJSEK, P., JOSKA, Z., POKORNÝ, Z., DOBROCKÝ, D., STUDENÝ, Z. (2019). Effect of Nitriding on the Microstructure and Mechanical Properties of Stainless Steels. In: Manufacturing Technology, Vol. 19, 2019, No. 5, p. 745-748. ISSN: 1213-2489.

[3] PILCH, O., FALTEJSEK, P., HRUBÝ, V., KRBATTA, M. (2017). The Corrosion Resistance of Turbocharger Stator after Plasma Nitriding Process. In: Manufacturing Technology, Vol. 17, 2017, No. 3, p. 360-364. ISSN: 12132489.

[4] LI, G., LIANG, Y., YIN, C., SUN, H., ZHU, Z. (2019). Study of M50NiL steel under carburizing and nitriding duplex treatment. In: Surface and Coatings Technology, Vol. 375, 2019, p. 132142. ISSN: 0257-8972.

[5] KŘíŽ, A., BRICÍN, D., PRŮCHA, V. (2018). The Potential for Heat Treating Cemented Carbides. In: Manufacturing Technology, Vol. 18, 2018, No. 4, p. 600-604. ISSN: 1213-2489.

[6] PENG, Y., LIU, Z., CHEN, CH., GONG, J., SOMMERS, M.A.J. (2020). Effect of low-temperature surface hardening by carburization on the fatigue behaviour of AISI 316L austenitic stainless steel. In: Materials Science and Engineering: $A$, Vol. 769, in progress (2 January 2020). ISSN: 0921-5093.

[7] BRUNATTO, S.F., SCHEUER, C.J., BOROMEI, I., CESCHINI, L., CARDOSO, R.P. (2018). Martensite coarsening in low-temperature plasma carburizing. In: Surface and Coatings Technology, Vol. 350, 2018, p. 161-171. ISSN: 0257-8972.

[8] SEDLÁK, J., POLZER, A., CHLADIL, J., SLANÝ, M., JAROŠ, A. (2017). Reverse Engineering Method Used for Inspection of Stirrer's Gearbox Cabinet Prototype. In: $M M$ Science Journal, Vol. 4, 2017, p. 1877-1882. ISSN: 1803-1269.

[9] HERRING, D.H. (2012). Vacuum heat treatment: Principles, Practices, Application. United States of America: BNP Media II, LLC, Troy, MI 48084, 2012. ISBN: 978-0-9767565-0-7.

[10] NUNES, R.F. (1991). ASM Handbook: Volume 4: Heat Treating. ASM International, USA, 1991. ISBN: 0-87170-379-3.

[11] DONG, M. et al. (2017). Vacuum carburization of $12 \mathrm{Cr} 2 \mathrm{Ni} 4 \mathrm{~A}$ low carbon alloy steel with lanthanum and cerium ion implantation. In: Journal of Rare Earths, Vol. 35,2017, No. 11, p. 1164-1170. ISSN: 1002-0721.

[12] CHEN, K., JIANG, Z., LIU, F., YU, L., LI, Y., GONG, W., CHEN, CH. (2019). Effect of quenching and tempering temperature on microstructure and tensile properties of microalloyed ultra-high strength suspension spring steel. In: Materials Science and Engineering: $A$, Vol. 766, 2019, 138272, ISSN: 0921-5093.

[13] ISO 18203. Steel - Determination of the thickness of surface-hardened layers.

[14] ASTM G 171-03. Standard Test Method for Scratch Hardness of Materials Using a Diamond Stylus. 